\title{
Trilha interpretativa como estratégia de educação em saúde: potencial para o trabalho multiprofissional e intersetorial
}

Maria Elisabeth Kleba ${ }^{(a)}$

Liane Colliselli ${ }^{(b)}$

Altamir Trevisan Dutra ${ }^{(c)}$

Eliara Solange Müller ${ }^{(d)}$

\section{Introdução}

O Ministério da Saúde vem, ao longo das duas últimas décadas, incentivando e implementando dispositivos que promovam a integralidade como diretriz orientadora de práticas de cuidados e de educação desenvolvidas nos serviços do Sistema Único de Saúde. A Estratégia Saúde da Família (ESF) é um desses dispositivos, estabelecendo, entre suas características: a integralidade da assistência, a abordagem multiprofissional, o estímulo à ação intersetorial e à participação da comunidade. Em 2012, o Ministério da Saúde reitera a ESF como central na implementação da Política Nacional de Atenção Básica, caracterizada "[...] por um conjunto de ações de saúde, no âmbito individual e coletivo, que abrange a promoção, a proteção da saúde [...] e a manutenção da saúde com o objetivo de desenvolver uma atenção integral" . ${ }^{1}$ (p. 19)

A atenção integral implica novas práticas de cuidado e de gestão, nas quais profissionais de saúde e usuários assumam a corresponsabilidade na construção das condições favoráveis à saúde pessoal e coletiva. Relações de vínculo e cooperação devem ser a base da interação em prol do bem-estar comum, o que requer processos de comunicação pautados no respeito, no compromisso, mas, também, na disponibilidade e na confiança mútua, atitudes que devem orientar as propostas de educação em saúde, seja no âmbito dos serviços, seja nas comunidades.

Nessa perspectiva, a Organização Mundial da Saúde salienta a promoção da saúde como um processo promovido junto com a população, não sobre ou para ela, para o que as pessoas necessitam ter garantidos direitos, recursos e oportunidades, com vistas a que suas contribuições sejam ampliadas e apoiadas. A promoção da saúde envolve o fortalecimento das habilidades das pessoas para agir, mas, também, a capacidade de grupos, organizações e da comunidade para influenciar os determinantes e condicionantes da saúde ${ }^{2}$.

Os profissionais de saúde assumem, dessa forma, uma responsabilidade para além de sua atuação clínica, tendo como foco o fortalecimento das pessoas e da comunidade em sua capacidade de tomar decisões e agir favoravelmente em prol da saúde. A Carta de Ottawa refere o reforço à ação comunitária como um dos campos da promoção da saúde, e salienta que o desenvolvimento das

\footnotetext{
(a) Área de Ciências da Saúde, Universidade Comunitária da Região de Chapecó. Avenida Senador Atílio Fontana, 591-E, Bairro Efapi. Chapecó, SC, Brasil. 89809-000.Ikleba@ unochapeco.edu.br (b) Curso de Enfermagem, Universidade Federal da Fronteira Sul. Chapecó SC, Brasil. liane.colliselli@ uffs.edu.br

(c) Área de Ciências da Saúde, Universidade Comunitária da Região de Chapecó. Chapecó, SC, Brasil. miri@unochapeco.edu.br (d) Área de Ciências Exatas e Ambientais, Universidade Comunitária da Região de Chapecó. Chapecó SC, Brasil.eliara@ unochapeco.edu.br
} 
comunidades se dá por meio do apoio social e do fortalecimento de sua capacidade de autoajuda, a partir dos recursos humanos, materiais e ambientais que essas disponibilizam². Nessa direção, a educação em saúde é apontada como estratégia essencial na promoção da saúde, para garantir informações e conhecimentos necessários à efetiva participação e ao empoderamento das pessoas e da comunidade ${ }^{2}$.

Contribuir para a ampliação da autonomia e o empoderamento das pessoas requer ações e processos educativos autênticos, que oportunizem as pessoas assumirem a condição de sujeitos criativos, capazes de transformar a realidade e, a partir dessa transformação, transformar a si mesmos. O ser humano pode assumir papel ativo na história, intervindo de forma favorável sobre as condições que oprimem e que desumanizam, à medida que toma consciência de que a realidade pode ser transformada, e, ao mesmo tempo, de que ele é capaz de agir em prol dessa transformação ${ }^{3}$. Para Freire, educador e educando se reconhecem parceiros no ato, não apenas de desvelar a realidade e, dessa forma, conhecê-la de forma crítica, mas, também, de recriá-la, reconhecendo-se - na reflexão e ação compartilhada - seus refazedores permanentes ${ }^{4}$.

Nessa perspectiva, a Política Nacional de Educação Popular em Saúde, que contempla, entre seus objetivos, o incentivo ao protagonismo popular na melhoria de suas condições de saúde, enfatiza a importância de vivenciar " [...] experiências significativas como potências de transformação do contexto vivido, produzindo conhecimento e cultura" 5 (p. 10).

Ter a emancipação como referencial no fazer cotidiano da saúde, pressupõe a construção de processos de trabalho onde os diversos atores possam se constituir sujeitos do processo de saúde e doença, contrapondo-se às atitudes autoritárias e prescritivas e radicalizando o conceito da participação nos espaços de construção das políticas da saúde em busca do inédito viável. ${ }^{5}$ (p. 6)

A proposta pedagógica aqui apresentada tem como diretriz orientadora a conformação de métodos e estratégias para a educação em saúde no exercício do trabalho, cumprindo o Art. 14 da Lei Orgânica da Saúde. Educação em saúde percebida como estratégia de promoção da saúde, com eixo orientador na integralidade articulada com a participação ativa da comunidade. Nesta perspectiva, foi adotada a trilha interpretativa como prática pedagógica, com o objetivo de promover a percepção das pessoas e instigar à reflexão sobre temas relacionados à saúde, de interesse de comunidades específicas.

O Programa Nacional de Reorientação da Formação Profissional em Saúde (Pró-Saúde) tem, entre suas estratégias, a premissa da integração do ensino com o serviço e a comunidade, com vistas a oportunizar, aos estudantes, práticas de ensino, pesquisa e produção de conhecimento mais próximas das reais necessidades dos usuários e dos serviços de saúde ${ }^{6}$. A Universidade Comunitária da Região de Chapecó (Unochapecó) vem implementando seus projetos aprovados nos editais do Pró-Saúde, desde 2005, em parceria com os serviços de saúde do município de Chapecó e demais municípios da Região de Saúde do Oeste do Estado de Santa Catarina, localizado no Sul do Brasil.

Este artigo relata uma atividade desenvolvida com inserção em um desses projetos, como atividade interdisciplinar e multiprofissional de promoção da saúde no município de Caibi (SC), situado, aproximadamente, a $90 \mathrm{~km}$ de Chapecó (SC). As ações foram planejadas e desenvolvidas em conjunto por estudantes e professores dos cursos de: Ciências Biológicas, Educação Física, Enfermagem, Farmácia, Fisioterapia, Nutrição, Psicologia e Serviço Social, em parceria com técnicos da Unochapecó, com a equipe da ESF e trabalhadores de outros setores daquele município.

\section{Trilhas interpretativas como prática pedagógica no ensino da saúde}

A experiência de utilizar trilhas interpretativas como prática pedagógica no ensino da saúde é resultado da articulação dos projetos Vivências Interdisciplinares Multiprofissionais no Meio Rural (VIM Rural) e Natureza, Saúde e Bem-Estar (NSBE), vinculados à proposta aprovada pela Unochapecó no edital do Pró-Saúde, em 2008. O VIM Rural visa incentivar e proporcionar ações de promoção e proteção da saúde às populações residentes no meio rural, por meio da articulação 
entre estudantes, professores e técnicos da Unochapecó com profissionais da saúde e outros atores vinculados aos municípios parceiros. O NSBE visa promover atividades interdisciplinares que assegurem uma abordagem integral do processo saúde-doença, despertando para a importância do lazer, das atividades físicas e da conservação ambiental para uma melhor qualidade de vida.

A proposta foi inicialmente incentivada por meio do VIM Rural e partiu da inserção do curso de Fisioterapia no Estágio de Vivências do curso de Agronomia (EVA) da Unochapecó. No EVA, os estudantes participam do cotidiano de famílias agricultoras, com vistas a conhecer sua realidade e formular propostas de melhorias, tanto na renda familiar, quanto nas condições de vida. A cada ano, o curso de Agronomia identifica um município da região interessado em receber o EVA, e discute com os gestores locais a proposta, contemplando: um diagnóstico do município, a vivência dos estudantes junto aos agricultores familiares e um plano elaborado pelos estudantes com sugestões para o desenvolvimento local, a partir das potencialidades identificadas junto às famílias e ao município.

A principal ação educativa planejada pelos projetos VIM Rural e NSBE em Caibi foi uma adaptação da trilha interpretativa. A trilha interpretativa é utilizada para

[...] promover a percepção das pessoas, de modo a despertar o interesse pela conservação de um espaço ao qual elas têm acesso e possibilitar maior contato com as espécies; quando bem planejada, serve de instrumento pedagógico para o ensino e o cuidado com os elementos da natureza, proporcionando maior contato entre o ser humano e a natureza. ${ }^{7}$ (p. 639)

Em sua proposta fundamental, a trilha interpretativa tem sempre um tema central, com uma introdução, uma sequência lógica de paradas predefinidas (estações temáticas) e uma conclusão. As trilhas ocorrem em ambientes naturais e possibilitam, aos participantes, atividades físicas. A proposta da trilha interpretativa em Caibi aconteceu durante três semestres. Inicialmente, professores, estudantes, técnicos da Unochapecó e profissionais da Prefeitura do município de Caibi foram mobilizados e convidados para participar das ações. Na sequência, os temas de interesse da equipe de saúde e outros setores do município foram identificados, a partir dos quais foi organizado o roteiro da primeira trilha interpretativa. Após esta primeira experiência, foi planejada a segunda trilha interpretativa. Durante o processo, outras atividades assistenciais e educativas foram desenvolvidas com: a unidade de saúde local, as residências de moradores urbanos e rurais, a comunidade e o conselho municipal de saúde.

No primeiro semestre de 2010, dez professores de diferentes cursos da Unochapecó dialogaram com o curso de Agronomia (que iniciara ações do EVA no município) e com representantes do município de Caibi, visando organizar os primeiros encaminhamentos para desenvolver ações em parceria, na perspectiva do VIM Rural articulado ao NSBE. O município de Caibi tem seis mil e trezentos habitantes, uma Unidade Básica de Saúde, na qual atuam três equipes da ESF, além de outros profissionais da saúde, num total de 48 trabalhadores. Conta, ainda, com um pequeno hospital de 33 leitos, o qual oferece serviços especializados e de apoio diagnóstico, utilizados, também, pela rede de atenção primária à saúde .

O gestor da saúde e as equipes da ESF local foram envolvidos desde o início em todas as etapas do planejamento das ações, sendo incorporados, ainda, profissionais de outros setores da administração pública, como: assistência social, educação, agronomia e esporte. A constituição de uma equipe de coordenação intersetorial viabilizou maior aproximação da universidade (estudantes, professores e técnicos) com as lideranças locais, favorecendo que fossem contemplados aspectos relevantes da realidade local, para facilitar a visualização de estratégias de intervenção mais adequadas à população. Isso facilitou a inserção dos estudantes no território para reconhecer problemas e potenciais do município, e, com isto, planejar ações educativas mais coerentes com as necessidades e interesses da população, considerando, no processo ensino-aprendizado, os saberes e as práticas dos profissionais e dos usuários.

Foram mobilizados quarenta estudantes de graduação, sendo a atividade desenvolvida como estágio nos cursos de Educação Física, Enfermagem e Nutrição, e como atividade curricular complementar nos cursos de Farmácia, Fisioterapia, Psicologia, Ciências Biológicas e Serviço Social. 
O primeiro desafio foi a constituição de um grupo de trabalho interdisciplinar, multiprofissional, no qual os participantes foram motivados a reconhecer, em seus saberes específicos, potências de diálogo criativo.

Inicialmente, os encontros de estudo e planejamento aconteciam em salas de aula da Unochapecó a cada 15 dias, no horário entre 17h e 18h, para facilitar a presença dos estudantes e professores. Nesses encontros eram compartilhados experiências e conhecimentos, bem como, elaboradas estratégias de interação com o município. Informações sobre o município (históricas, sociais, demográficas e epidemiológicas), estudos sobre os princípios da atenção básica e o aprofundamento de conceitos, como integralidade, trabalho em equipe e promoção da saúde, foram fundamentais a fim de se reconhecerem pontos convergentes e complementares dos saberes específicos de cada curso na formulação da proposta.

A cada duas semanas, um grupo de representantes deslocava-se a Caibi, buscando ampliar informações sobre o município, bem como, definir, de forma articulada, estratégias e ações com a equipe de coordenação local do projeto. Nesses encontros, foram estabelecidas, como estratégias prioritárias, ações educativas de caráter coletivo que pudessem promover maior participação da comunidade, como forma de ampliar sua autonomia em seu autocuidado, no cuidado à coletividade e ao meio ambiente, assim como no controle social sobre a política de saúde do município'.

No segundo semestre de 2010, a trilha interpretativa - denominada "Promoção da Saúde" - foi desenvolvida no Parque Municipal Água Mineral, um local de convívio social do município, que conta com espaço arborizado, com bastante sombra, riacho próximo e um campo para a prática de atividades físicas, considerado espaço ideal para realização das atividades previamente planejadas pelo projeto. Os participantes da trilha interpretativa foram famílias residentes na área rural e alunos da Casa Familiar Rural (escola), perfazendo um total de oitenta pessoas, e teve duração de quatro horas. Cada estação foi assumida por estudantes e docentes de um curso específico, mais afim à temática selecionada. Estudantes de Enfermagem desenvolveram uma atividade educativa abordando informações sobre agrotóxicos e hanseníase, tema sugerido pelos profissionais do município com base nos dados epidemiológicos; estudantes do curso de Fisioterapia desenvolveram ações relacionadas à ergonomia/postura corporal a serem observadas durante o desenvolvimento do trabalho na agricultura e nos serviços domésticos; estudantes de Nutrição orientaram sobre a importância da produção e do consumo de alimentos saudáveis, proporcionando degustação de alimentos; estudantes vinculados ao curso de Educação Física desenvolveram atividades de movimento corporal, enfatizando a importância da atividade física na vida diária; estudantes de Ciências Biológicas e Agronomia orientaram sobre cuidados com a água e a conservação do meio ambiente; estudantes de Psicologia e do Serviço Social desenvolveram atividades lúdicas e educativas, problematizando a violência e a proteção dos direitos humanos, especialmente voltados para crianças, adolescentes e mulheres.

A trilha interpretativa foi realizada, em síntese, no seguinte formato: para iniciar a trilha, todos os participantes foram reunidos, acolhidos pelos organizadores do evento e orientados sobre $o$ objetivo e a metodologia da atividade e da proposta. Em seguida, os participantes foram divididos em seis pequenos grupos, sendo cada grupo conduzido para uma das estações temáticas da trilha, contando com um monitor para facilitar o trajeto entre as estações. Em cada parada, nas estações, os participantes eram envolvidos com metodologias educativas ativas, de acordo com a temática definida, que duravam em torno de vinte minutos. Este tempo era monitorado e, por meio do som de um apito, era sinalizado o término da atividade na estação; então, os participantes eram conduzidos à estação seguinte. No percurso da caminhada até a próxima estação, eram promovidas atividades de alongamento e de observação da natureza, valorizando esta ação como estratégia de promoção da saúde. Quando todos os grupos haviam percorrido as seis estações, os participantes foram novamente reunidos e, com os agradecimentos, foram instigados a ocupar melhor os espaços verdes e de lazer do município, valorizando-os como espaços de convivência saudável e de promoção da saúde.

$\mathrm{Na}$ avaliação após a realização da trilha, os estudantes ressaltaram, como ponto frágil da proposta, a pouca interação com os profissionais do município, os quais assumiram papel de ouvintes no dia da atividade, apesar de garantirem total apoio e condições objetivas para sua realização. Outro ponto crítico ressaltado foi o fato de os estudantes da graduação terem atuado por curso, de forma 
independente, em quatro das seis estações, sendo que a atividade deveria ter caráter interdisciplinar e multiprofissional. Apesar dessas ponderações, o grupo avaliou a experiência como muito positiva, decidindo propor, ao município, uma segunda edição da trilha interpretativa no semestre seguinte. Nesta segunda trilha, foram propostas como metas: sensibilizar a equipe de profissionais de saúde do município para atuar como parceira, bem como, organizar as estações por temas que viabilizassem a atuação dos estudantes de forma multiprofissional.

\section{A segunda trilha interpretativa: Saúde e meio ambiente: patrimônio do povo}

No primeiro semestre de 2011, as discussões e o planejamento coletivo entre os atores da Unochapecó e do município de Caibi foram retomados. Neste semestre, a trilha interpretativa foi estruturada na praça central do município, local com gramado e árvores, adequado à implementação da caminhada e da organização das estações educativas. A escolha do local levou em consideração o desejo de dar maior visibilidade à atividade no município, valorizando o envolvimento da equipe de saúde e outros setores na realização de ações de promoção da saúde. Esta trilha interpretativa recebeu o nome de Saúde e meio ambiente: patrimônio do povo, destacando-se o tema da $14^{\text {a }}$ Conferência Nacional de Saúde, com chamada para novembro daquele ano pelo Ministério da Saúde no Brasil.

A definição do público-alvo levou em consideração a sugestão de profissionais da ESF local, para identificar pessoas que pudessem ser multiplicadores dos conhecimentos com diferentes organizações no município. Com este objetivo, foram convidadas integrantes dos grupos de mães de 21 comunidades rurais do município, obtendo-se a participação de sessenta mulheres. Também foram convidados: alunos da Casa Familiar Rural, grupo de idosos, de tabagismo, de diabéticos/hipertensos, Alcoólicos Anônimos, agentes comunitárias de saúde e demais profissionais da equipe que não atuaram como promotores da dinâmica nas estações, além de outras lideranças do município. Ao todo, participaram cento e vinte pessoas.

Nessa edição, cada uma das estações foi planejada e implementada em parceria entre professores e estudantes dos cursos da Unochapecó (Ciências Biológicas, Educação Física, Enfermagem, Farmácia, Fisioterapia, Nutrição, Odontologia, Psicologia, Serviço Social e Agronomia), profissionais da ESF, da educação e de outros setores do município, bem como, lideranças indicadas pela equipe de saúde local, na perspectiva da interdisciplinaridade e intersetorialidade. Cada tema trabalhado foi organizado a partir dos dados levantados pelos profissionais da saúde no município, por exemplo: a temática "água: agrotóxico e lixo" foi inserida na trilha em virtude do aumento do número de intoxicações por agrotóxicos em Caibi (em 2008, foram notificados 12 casos; em 2009, 22 casos; e, em 2010, trinta casos), o que poderia estar relacionado com o uso incorreto dos equipamentos de proteção pessoal (EPIs), com a contaminação dos alimentos e/ou água e, possivelmente, com o destino incorreto das embalagens dos agrotóxicos.

As estações temáticas da trilha foram organizadas buscando-se trabalhar conteúdos por meio de metodologias lúdicas e interativas, contemplando os seguintes temas: 1) sexualidade no ciclo evolutivo, da adolescência ao idoso; 2) respeito e convivência saudável entre indivíduo, família e comunidade; 3 ) práticas de violência e cultura da paz; 4) práticas de lazer saudável frente ao consumo de tabaco, álcool e outras drogas; 5) água: agrotóxico e lixo; 6) uso da automedicação, plantas medicinais, espiritualidade e fitoterápicos.

Durante o desenvolvimento das atividades pedagógicas, objetivou-se a reflexão sobre a importância das ações individuais e coletivas, em parceria com as instituições e com o poder público, na promoção e na proteção da saúde, promovendo-se reflexão sobre causas e possíveis consequências quando o empenho e a colaboração dos envolvidos não ocorrem.

Os integrantes responsáveis pelas estações temáticas tinham tarefas comuns, entre as quais a preocupação de incentivar os indivíduos na prática do autocuidado, promovido por meio das dinâmicas de interação com os participantes em cada atividade desenvolvida. A interação vivenciada na trilha - entre estudantes, docentes, profissionais do município e população - trouxe impactos positivos enquanto processo de aprendizagem. Assim, demonstra que é possível realizar ações intersetoriais quando todos refletem a respeito de cada atribuição específica, sem fragmentar a sua atenção/cuidado. 
Nesta segunda edição da trilha interpretativa, o número de pessoas que compareceram ao local superou as expectativas, e a maioria dos participantes foi receptiva à proposta desenvolvida, demonstrando: interesse, envolvimento, iniciativa, espírito de liderança e atitudes cooperativas. Ao final das atividades, percebeu-se que os visitantes estavam satisfeitos com as informações recebidas durante a tarde e refletiram acerca da necessidade de rever alguns hábitos, como afirmam as agricultoras: "Acho que foi muito proveitosa, tudo o que vier pra gente saber a mais, acho que é válido!" (A1); "Tudo o que foi tratado a gente vai usar no dia a dia." (A2); "Todas elas (estações) foram importantes. Cada uma com sua parte, sua mensagem. A gente vai aproveitar, para nossa família..." (A3).

Para o grupo envolvido na organização (professores e estudantes da Unochapecó e profissionais do município de Caibi), a trilha possibilitou o desenvolvimento de ações interdisciplinares e multiprofissionais, o que oportunizou, aos estudantes dos diferentes cursos, a aplicação de seus conhecimentos com certa autonomia e, ao mesmo tempo, de forma interdependente. Na opinião dos estudantes, a atividade permitiu a vivência de uma nova experiência, um novo método de trabalho, pois promoveu a integração de acadêmicos e destes com a comunidade. Atividades interdisciplinares são de extrema importância na formação do profissional, pois, no decorrer da carreira, ele sempre estará em contato com profissionais de outras áreas, e isto potencializa o enriquecimento das ações.

Além disso, a atividade propiciou ao grupo intervir na realidade por intermédio da partilha de saberes e experiências, e, com isso, capacitar os indivíduos e a comunidade para a busca ativa da promoção da saúde e de condições para uma existência digna. A educação popular caracteriza-se como prática político-pedagógica emancipatória, visando à

[...] promoção da autonomia das pessoas, à horizontalidade entre os saberes populares $\mathrm{e}$ técnico-científicos, à formação da consciência crítica, à cidadania participativa, ao respeito às diversas formas de vida, à superação das desigualdades sociais e de todas as formas de discriminação, violência e opressão. ${ }^{5}$ (p. 9)

Para os professores, a atividade foi um desafio, proporcionando a realização de orientações e tutorias para estudantes de diferentes cursos e profissionais do município de Caibi, além de possibilitar a aproximação dos cursos da saúde. Os professores tiveram papel de facilitadores, mediando conflitos, valorizando iniciativas e promovendo o diálogo reflexivo, criativo. Freire 4 reforça o papel da educação como prática de liberdade, por meio da qual o educador promove, com os educandos, a problematização do conhecimento, desafiando-os a assumirem papel de investigadores críticos, a buscarem a emersão da consciência, o desvelamento da realidade, de forma que possibilite sua inserção criativa e tranformadora. Não apenas o educador educa, mas ambos, educador e educando, educamse, tornando-se, desta forma, sujeitos, em diálogo, do processo ensino-aprendizagem; " [...] os homens se educam em comunhão, mediatizados pelo mundo." ${ }^{4}$ (p. 39)

Da mesma forma, a equipe local de saúde revelou potenciais favoráveis ao desenvolvimento de ações de promoção da saúde, tendo participação ativa e comprometida nas atividades realizadas junto à trilha interpretativa. Esta demonstrou ser, assim, uma possibilidade viável e produtiva de promoção à saúde, abrindo novos horizontes e possibilidades que podem ser adequadas e aperfeiçoadas conforme a realidade local.

A Política Nacional de Atenção Básica orienta que os profissionais de saúde devem "[...] identificar parceiros e recursos na comunidade que possam potencializar [...] [e] desenvolver ações intersetoriais, integrando projetos e redes de apoio social, voltados para o desenvolvimento de uma atenção integral" 1 (p. 11). Para Acioli ${ }^{9}$, o processo pedagógico deve tomar como ponto de partida "[...] o saber anterior das pessoas, acreditando que todos têm um conhecimento a partir de suas experiências e vivências, de suas condições concretas de existência" (p. 118). Além disso, a abertura para construir novos conhecimentos, com base na (com)partilha de saberes técnicos e saberes populares, exige humildade e o reconhecimento de "[...] que os diversos saberes são apenas diferentes, e não hierarquizados, e que a experiência vale tanto quanto a teoria"9 (p. 118).

Dialogar implica humildade, quando um abre-se à palavra do outro, sentindo-se e reconhecendo-se tão homem quanto o outro, o que favorece chegar ao lugar de encontro, onde ambos, em comunhão, 
buscam saber mais. Diálogo implica, também, confiança, relações horizontais, quando cada sujeito implicado testemunha, aos outros, suas reais intenções ${ }^{4}$.

O diálogo não é imposição ou disputa de ideias, mas envolve um profundo sentimento de reciprocidade diante das diferenças: um fala com o outro, buscando ouvir, na diferença, a complementariedade.

O reconhecimento da alteridade é o que cria a possibilidade do diálogo. A anulação das diferenças não permite diálogo; portanto, uma intervenção pedagógica pautada na obra de Paulo Freire é baseada na convicção de que o novo surge somente do encontro entre diferentes que apresentem uma disponibilidade mútua para a ação criativa. $^{10}$ (p. 567)

A Carta de Ottawa ${ }^{2}$ salienta que a promoção da saúde busca fortalecer o poder das comunidades, para que se apropriem e exerçam controle sobre seu próprio destino. Aqui cabe uma reflexão sobre o conceito de comunidade, definida, usualmente, como um conjunto de indivíduos que vivem em uma mesma área geográfica, com uma cultura, necessidades e interesses comuns. Muito mais do que elementos comuns, podemos encontrar, nas comunidades, diversidades e contrariedades que geram divisões (interesses religiosos, partidários, conflitos por terra etc.). Ao invés de um conjunto de indivíduos, a comunidade revela um conjunto de redes de sociabilidade e de poder, em que se articulam interesses comuns com interesses distintos e contraditórios ${ }^{11}$.

Em processos pedagógicos de interação com a comunidade, com vistas à promoção da saúde, é necessário reconhecer e construir parcerias com os distintos grupos sociais, os quais podem promover resistência, apatia ou apoio frente às ações desenvolvidas pelos atores institucionais. Por meio da conformação de concepções, hábitos e práticas, as redes sociais criam identidades, para promover a inclusão ou a exclusão de seus membros. Desta forma, as redes sociais são produtoras de capital social à medida que favorecem relações horizontais, fortalecendo a autoestima e promovendo a reciprocidade. Redes sociais podem, no entanto, reproduzir relações de domínio e de alienação, quando impõem relações verticais, autoritárias ou paternalistas, promovendo clientelismo e tutela e fortalecendo a insegurança e a dependência ${ }^{11}$. Em contrapartida, a ação comunicativa pode proporcionar a percepção de descontinuidades estruturais baseadas em discrepâncias de poder, valores, conhecimento e interesses, desvelando processos culturais e organizativos que as reproduzem ou transformam ${ }^{11}$. A ESF pode promover a saúde da / e com a comunidade, à medida que reconhece sua capacidade de autogestão e valoriza os esforços das redes sociais em participarem no enfrentamento dos problemas que se relacionam com a saúde (habitação, alimentação, trabalho e renda, entre outras dimensões), sem perder de vista as contradições e os conflitos existentes.

Em relação às parcerias e o trabalho em equipe, destaca-se que

[...] na interdisciplinaridade um fato importante a considerar é que tudo que envolve a vida não pode mais ser tratado de forma fragmentada, sob o risco de não ser compreendido ou de não alcançar resolutividade. Porque a vida é complexa, o cuidar da vida também exige complexidade de ações, o que nos levará, necessariamente, a buscar parceiros. ${ }^{12}$ (p. 219)

A atenção integral visa produzir impactos nos determinantes e condicionantes de saúde das coletividades, além de fortalecer a autonomia das pessoas em sua capacidade de autocuidado, o que requer que as pessoas sejam consideradas em sua singularidade e inserção sociocultural ${ }^{1}$. Nas trilhas interpretativas implementadas, em cada estação, foi garantida a inclusão de um tema positivo, frente ao problema priorizado como foco do trabalho educativo, com vistas a ressaltar potencialidades locais favoráveis ao enfrentamento dos problemas identificados.

O sentido de pertencimento presente nas práticas de educação popular em saúde contribui para o fortalecimento de identidades e do espírito de coletividade, como é expresso nas redes construídas pelos coletivos, movimentos, articulações de nível nacional e local, necessários para ampliação da qualidade da saúde das populações. ${ }^{5}$ (p. 12) 
Além de diversificarem os cenários de prática, as trilhas interpretativas favoreceram o protagonismo dos estudantes, em diálogo com os atores locais, promovendo o reconhecimento de problemas e potencialidades de territórios rurais, de forma que estes valorizem iniciativas e recursos existentes nessas localidades.

\section{Conclusões}

Esta experiência possibilitou apreender novas possibilidades a serem realizadas como ação de promoção da saúde e atividades educativas no setor saúde. A trilha interpretativa, além de unir a equipe multiprofissional da área da saúde, possibilitou sua interação com outros setores da administração pública e da sociedade em geral, destacando seu papel em prol do desenvolvimento da comunidade. Além disso, oportunizou o envolvimento da comunidade de forma lúdica em atividades educativas, sensibilizando-a para a valorização dos espaços de lazer que o município dispõe, bem como, dos potenciais existentes para o enfrentamento dos problemas de saúde.

O VIM Rural e o NSBE - projetos inseridos no Pró-Saúde da Unochapecó - oportunizaram uma experiência de interação efetiva da instituição de ensino com a rede de serviços da atenção básica, o que possibilita o desenvolvimento de práticas de atenção à saúde junto aos diferentes grupos em um município do oeste catarinense. Estudantes apropriaram-se de estratégias educativas dialógicas, desempenhando papel ativo no planejamento, implementação e avaliação das atividades. Destaca-se a integração ensino-serviço-comunidade, que oportuniza a aprendizagem sobre a realidade da região, com destaque na área rural, pouco abordada como cenário de práticas nas universidades, assim como sobre estratégias de promoção da participação da comunidade nas ações de saúde.

Esta vivência fortaleceu o processo de reorientação da formação profissional em saúde em curso no Brasil, com vistas a consolidar a implementação do Sistema Único de Saúde, tendo a educação em saúde, a integralidade, a atenção básica, a participação da comunidade e a promoção da saúde como focos prioritários. Favoreceu a aproximação do processo de formação à realidade local/regional, tanto em relação às necessidades de saúde da população, quanto às demandas e potenciais dos serviços de saúde.

\section{Agradecimentos}

Os autores agradecem ao Ministério da Saúde, pelos recursos disponibilizados por meio do Programa Nacional de Reorientação da Formação Profissional em Saúde (Pró-Saúde); ao Secretário Municipal e trabalhadores da saúde do município de Caibi, Santa Catarina, pelo apoio e parceria; aos professores, estudantes e gestores da Universidade Comunitária da Região de Chapecó (Unochapecó), pela confiança, apoio e participação efetiva no desenvolvimento do projeto; e, em especial, à Professora Sabrina Fiorentin (in memoriam), autora do projeto VIM Rural. 


\section{Colaboradores}

Maria Elisabeth Kleba participou de todas as etapas de elaboração do artigo, de sua discussão e da revisão final do texto. Liane Colliselli, Altamir Trevisan Dutra e Eliara Solange Müller participaram da revisão bibliográfica, das discussões e da revisão do texto.

\section{Referências}

1. Ministério da Saúde. Secretaria de Atenção à Saúde. Política Nacional de Atenção Básica em Saúde. Brasília (DF): Ministério da Saúde; 2012.

2. Ministério da Saúde. Secretaria de Políticas de Saúde. Projeto Promoção da Saúde. As Cartas da Promoção da Saúde. Brasília (DF): Ministério da Saúde; 2002.

3. Freire P. Conscientização: teoria e prática da libertação - uma introdução ao pensamento de Paulo Freire. São Paulo: Centauro; 2001.

4. Freire P. Pedagogia do oprimido. Rio de Janeiro: Paz e Terra; 2005.

5. Ministério da Saúde. Secretaria de Gestão Estratégica e Participativa. Política Nacional de Educação Popular em Saúde. Brasília (DF): Comitê Nacional de Educação Popular em Saúde; 2012.

6. Ministério da Saúde. Programa Nacional de Reorientação da Formação Profissional em Saúde - Pró-Saúde: objetivos, implementação e desenvolvimento potencial. Brasília (DF): Ministério da Saúde; 2007.

7. Amaral AG, Munhoz CBR. Planejamento do traçado de uma trilha interpretativa através da caracterização da flora do parque ecológico e de uso múltiplo Águas Claras, DF. Rev Bras Biocienc. 2007; 5(1):639-41.

8. Instituto Brasileiro de Geografia e Estatística [Internet]. Cidades@ [acesso 2013 Jul 12]. Disponível em: http://www.cidades.ibge.gov.br/painel/painel. php?lang=\&codmun =420310\&se arch=santa-catarina \% 7Ccaibi\% 7Cinfograficos: -dadosgerais-do-municipio

9. Acioli S. A prática educativa como expressão do cuidado em Saúde Pública. Rev Bras Enferm. 2008; 61(1):117-21.

10. Soares LLM, Verissimo LJ. A formação do aluno na graduação em psicologia pela pedagogia de Paulo Freire. Psicol Cienc Prof. 2007; 30(3):588-603.

11. Keijzer B. Los discursos de la educación y participación en salud: de la evangelización sanitaria al empoderamiento. In: Minayo MCS, Coimbra CEA, organizadores. Críticas e atuantes: ciências sociais e humanas em saúde na América Latina. Rio de Janeiro: Fiocruz; 2005. p. 441-60.

12. Tavares CMA, Matos E, Gonçalves L. Grupo multiprofissional de atedimento ao diabético: uma perspectiva de atenção interdisciplinar à saúde. Texto Contexto Enferm. 2005; 14(2):213-21. 
Este relato tem por objetivo divulgar a experiência de uma trilha interpretativa, organizada a partir de um circuito com seis estações temáticas, entre as quais os participantes precisavam se deslocar/caminhar, desenvolvida por estudantes, professores e técnicos da Universidade Comunitária da Região de Chapecó, em conjunto com profissionais de um município do oeste catarinense, no Brasil. Foram realizadas duas trilhas em áreas verdes, as quais consideraram a realidade municipal, discutida com profissionais locais, para abordar nas seis estações, planejadas como atividades multiprofissionais e intersetoriais. As trilhas envolveram, aproximadamente, duzentas pessoas, incluindo: famílias agricultoras, alunos da Casa Familiar Rural, grupos de mulheres e lideranças locais. Destacam-se a integração ensino-serviço-comunidade, o desenvolvimento de estratégias educativas dialógicas, proatividade no planejamento, implementação e avaliação das ações, e a sensibilização quanto à importância da educação e da promoção da saúde pelos estudantes, profissionais e população local.

Palavras-chave: Promoção da Saúde. Educação em Saúde. Assistência integral à Saúde. Ação intersetorial. Equipe de assistência ao paciente.

\section{Interpretive trail as a health education strategy: potential for intersectoral and multiprofessional work}

This report had the aim of disseminating an experience of an interpretive trail that was organized starting from a circuit with six themed stations, among which the participants had to travel/walk. It was developed by students, teachers and technicians at the Community University of the Chapecó Region, together with professionals in a municipality in western Santa Catarina, Brazil. Two trails were made in green areas. These took municipal realities into account through discussions with local professionals so as to address the six stations, which were planned as multiprofessional and intersectoral activities. The trails involved approximately two hundred people, including farming families, students at the Rural Family House, women's groups and local leaders. Teachingservice-community integration, development of dialogical educational strategies, proactive planning, implementation and evaluation of actions and awareness about the importance of education and health promotion for students, professionals and local people were emphasized.

Keywords: Health promotion. Health education. Comprehensive health care. Intersectoral action. Patient healthcare team.

Ruta interpretativa como estrategia de educación en salud: potencial para el trabajo multi-profesional e inter-sectorial

El objetivo de este relato es divulgar la experiencia de una ruta interpretativa organizada a partir de un círculo con seis estaciones temáticas, entre las cuales los participantes precisaban desplazarse/caminar, desarrollada por estudiantes, profesores y técnicos de la Universidad comunitaria de la Región de Chapecó, en conjunto con profesionales de un municipio del oeste del Estado de Santa Catarina, Brasil. Se realizaron dos rutas en áreas verdes, que se consideraron la realidad municipal, discutida con profesionales locales para abordar en las seis estaciones, planificadas como actividades multi-profesionales e intersectoriales. las rutas envolvieron aproximadamente a doscientas personas incluyendo a familias agricultoras, alumnos de la Casa Familiar Rural, grupos de mujeres y liderazgos locales. Se destacan la integración enseñanza servicio-comunidad, el desarrollo de estrategias educativas dialógicas, pro-actividad en la planificación implementación y evaluación de las acciones y la sensibilización sobre la importancia de la educación y de la promoción de la salud por parte de los estudiantes, los profesionales y la población local.

Palabras clave: Promoción de la Salud. Educación en Salud. Asistencia integral a la salud. Acción inter-sectorial. Equipo interdisciplinar de salud. 